\title{
The UCS preexposure effect in taste aversion learning: Tolerance and blocking are drug specific
}

\author{
ROBERT J. DACANAY and ANTHONY L. RILEY \\ Psychopharmacology Laboratory, The American University, Washington, D.C. 20016
}

\begin{abstract}
Following drug preexposure, rats were given taste aversion conditioning in either the preexposure environment or the home cage. For animals preexposed to $\mathrm{LiCl}$, only the subjects conditioned in the preexposure environment showed the typical UCS preexposure effect, that is, an attenuated aversion, an effect consistent with a blocking interpretation of the LiCl-induced preexposure effect. On the other hand, all rats preexposed to morphine displayed attenuated aversions, independent of the preexposure and conditioning environments, an effect consistent with a pharmacological tolerance explanation of the UCS preexposure effect to morphine. The specific mechanism underlying the drug-induced attenuation appears to be drug-dependent.
\end{abstract}

While rats readily avoid consumption of solutions previously paired with a toxin (see Riley \& Clarke, 1977), this conditioned aversion is markedly attenuated if the rat has received exposure to the toxin prior to conditioning (see Braveman, 1977; Gamzu, 1977). This UCS preexposure effect is now well documented and is produced by a wide range of pharmacological agents, for example, $\mathrm{LiCl}$ (Batson \& Best, 1979; Riley, Jacobs, \& LoLordo, 1976), amphetamine (Cappell \& LeBlanc, 1975; Goudie \& Thornton, 1975), $\Delta^{9}$-THC (Goett \& Kay, 1981), chlordiazepoxide (Gamzu, 1977), alcohol (Eckardi, 1976), and morphine (Cappell, LeBlanc, \& Herling, 1975; Jacobs, Zeliner, LoLordo, \& Riley, 1981).

One possible explanation for the UCS preexposure effect in taste aversion learning is drug colerance (Cappell \& LeBlanc, 1977; Cappell \& Poulos, 1979; Riley et al., 1976). Tolerance, in general, refers to the decrease in the effect of a drug over repeated administrations, a decrease which presumably reflects pharmacokinetic (e.g., metabolic; Goldstein, Aronow, \& Kalman, 1974) or pharmacodynamic (e.g., receptor; Greengard, 1976) changes that reduce the efficacy of the drug to produce the measured response (see Corfield-Sumner \& Stolerman, 1978). Independent of the mechanism underlying this response weakening, when an animal is repeatedly injected with a toxin during UCS preexposure, the aversiveness of the drug may be reduced to a level insufficient to condition a subsequent aversion.

While the tolerance explanation has received con-

The authors would like to thank D. A. Zellner, J. M. Mastropaolo, A. L. Buller, and G. L. Daniels for their helpful criticisms and assistance. Requests for reprints should be sent to Anthony L. Riley or Robert J. Dacanay, Psychopharmacology Laboratory, Department of Psychology, The American University, Washington, D.C. 20016. siderable discussion (Cain \& Baenninger, 1977; Cannon, Baker, \& Berman, 1977; Cappell \& LeBlanc, 1977; Cappell \& Poulos, 1979; Eckardt, 1976; Jacobs et al., 1981; Riley et al., 1976), the recent work by Batson and Best (1979), Braveman (1979), Cappell and Poulos (1979), and Poulos and Cappell (1979) questions the general efficacy of drug tolerance to explain the UCS preexposure effect. For example, in the study by Batson and Best (1979), following $\mathrm{LiCl}$ preexposure, rats were given a saccharin-LiCl pairing in one of two environments. For one group of subjects, the conditioning environment was identical to that in which the drug had been preexposed. For the second group, conditioning occurred in a novel environment. Subsequent aversion tests revealed that only the group that was preexposed and conditioned in the same environment showed the typical UCS preexposure effect, that is, an attenuated aversion. Batson and Best (1979) suggested that this attenuation was due to the fact that contextual cues that had been paired with $\mathrm{LiCl}$ during preexposure blocked the subsequent conditioning to saccharin when the taste aversion conditioning was attempted in the same environment and thereby in the presence of the previously conditioned context (see Kamin, 1969). Because there is no a priori basis for assuming that pharmacological tolerance is environmentdependent, the fact that the UCS preexposure effect with $\mathrm{LiCl}$ is dependent upon the similarity of the preexposure and conditioning context is damaging to a general tolerance explanation of the drug-induced attenuation.

It should be noted that in the studies in which the UCS preexposure effect is reported to be environmentdependent, the preexposed drug was a drug to which little tolerance is evident, for example, $\mathrm{LiCl}$ (Cain \& Baenninger, 1977; Suarez \& Barker, 1978) and am- 
phetamine (Lemberger \& Rubin, 1976). It is still possible that pharmacological tolerance may mediate the UCS preexposure effect produced by drugs to which tolerance is rapidly acquired, for example, narcotics (Corfield-Sumner \& Stolerman, 1978; Martin \& Sloan, 1977; Mucha \& Kalant, 1980; Mucha, Kalant, \& Linesman, 1979).

In the following experiments, rats were preexposed and conditioned in the same or different environments. The drug which the subjects were preexposed to and conditioned with was either $\mathrm{LiCl}$ (Experiment 1) or morphine sulfate (Experiment 2). If blocking is the general mechanism underlying the UCS preexposure effect, this effect should be evident with both drugs and dependent upon the similarity of the preexposure and conditioning environments. On the other hand, if tolerance mediates the UCS preexposure effect of drugs to which tolerance readily occurs, it would be expected that, for such drugs, the preexposure effect would be evident independent of the similarity of the preexposure and conditioning environments. The present experiments test these predictions.

\section{EXPERIMENT 1}

\section{Method}

Subjects. The subjects were 24 experimentally naive rats of Long-Evans descent, approximately 90 days of age at the beginning of the experiment. The subjects were housed in individual wire-mesh home cages and were maintained on a 12 -h-light/12h-dark cycle for the duration of the experiment.

Apparatus. Drug preexposures were given in four identical $20 \times$ $18 \times 12 \mathrm{~cm}$ Plexiglas chambers with stainless steel grid floors (1-cm-diam rods spaced $2.5 \mathrm{~cm}$ center to center). These distinctive environments were located in a room separated from the animal's home cage. The ambient noise level was different for the distinctive and home cage environments. For each environment, fluids were made available from Nalgene tubes whose spouts protruded approximately $2 \mathrm{~cm}$ into the chambers.

Procedure. Prior to the initiation of this phase, the subjects were dıprived of water and given ad-lib access to food. On the following day (Day 1), the subjects were given 20-min access to water in the home cage. This habituation procedure was repeated for 13 consecutive days, at which point all subjects were approaching and drinking from the tube within $2 \mathrm{sec}$ of its presentation.

On Day 14, all subjects were placed in the distinctive environment and given 20-min access to water. At this point, differential treatment was administered to two groups of subjects matched on water consumption, Groups $\mathrm{L}$ and $\mathrm{W}$. Immediately following access to water, Group L was given an intraperitoneal (ip) injection of $1.8 \mathrm{mEq}, .15 \mathrm{M} \mathrm{LiCl}$ and returned to the distinctive environment for 20 additional minutes. After this time, Group L was returned to the home cage. Group W was treated similarly, except that following water access these subjects were given an equivolume ip injection of distilled water. On each of the following 3 days, both groups were given 20 -min access to water in the home cage followed by an ip injection of distilled water. This cycle of alternating drug preexposure and water recovery was repeated until all subjects had received five complete cycles.

On the day following the last preexposure cycle, Groups $\mathrm{L}$ and W were each divided randomly into two groups of subjects, Groups LE and LH and Groups WE and WH. On this day, Groups LE and WE were placed in the distinctive environment and given 20 - min access to a novel saccharin solution $(.1 \% \mathrm{w} / \mathrm{v}$, Fisher purified). Immediately following saccharin access, both of these groups were injected with $\mathrm{LiCl}$ and returned to the distinctive environment for $20 \mathrm{~min}$, at which point they were placed into their home cages. Groups LH and WH were given 20-min access to saccharin in the home cage followed immediately by an ip injection of $\mathrm{LiCl}$. On each of the following 3 days, all groups were given 20 -min access to water in the home cage followed immediately by an ip injection of distilled water.

This cycle of alternating conditioning and water recovery was repeated until all subjects had received three complete cycles. Following the last cycle, all subjects were given 20-min access to saccharin in their conditioning environments for a final aversion test.

\section{Results}

Over the water habituation days, the subjects gradually increased consumption of water, drinking a mean of approximately $13 \mathrm{ml}$ on the final 3 days of water adaptation.

On Day 1 of the preexposure phase, when all subjects were given their 20-min access to water in the experimental chamber, both Groups $L$ and $W$ decreased consumption below their previous day's water baseline in the home cage. Figure 1 illustrates this decrease in consumption on the first exposure to the experimental chamber (see Baseline and Preexposure 1).

With repeated access to water in the experimental chamber, each of which was followed by $\mathrm{LiCl}$ (Group L) or water (Group W), both groups showed a slight, nonsignificant increase in consumption, although neither group approximated its home cage water baseline (see Figure 1). At no point during this phase did Groups $\mathrm{L}$ and $\mathrm{W}$ differ in their consumption of water.

During the water recovery sessions following each preexposure injection, both groups returned to their preinjection water baseline, indicating that there was no residual effect of injections on water consumption.

Because the subjects in the two conditioning environments, that is, experimental chamber and home cage, consumed different amounts of saccharin prior to the saccharin- $\mathrm{LiCl}$ pairings, the subsequent aversions are indexed by the percentage shift in consumption from this initial baseline. Figure 2 illustrates this

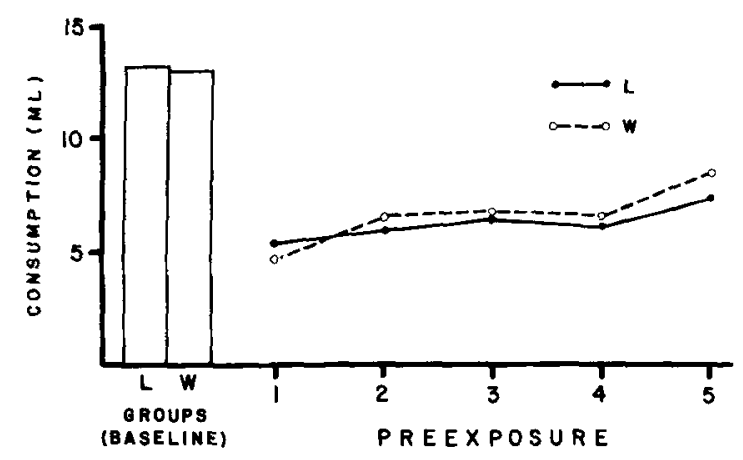

Figure 1. Mean consumption ( $\mathrm{ml}$ ) of water during habituation in the home cage and over the preexposure injections in the distinctive environment for Groups $L$ and $W$. 


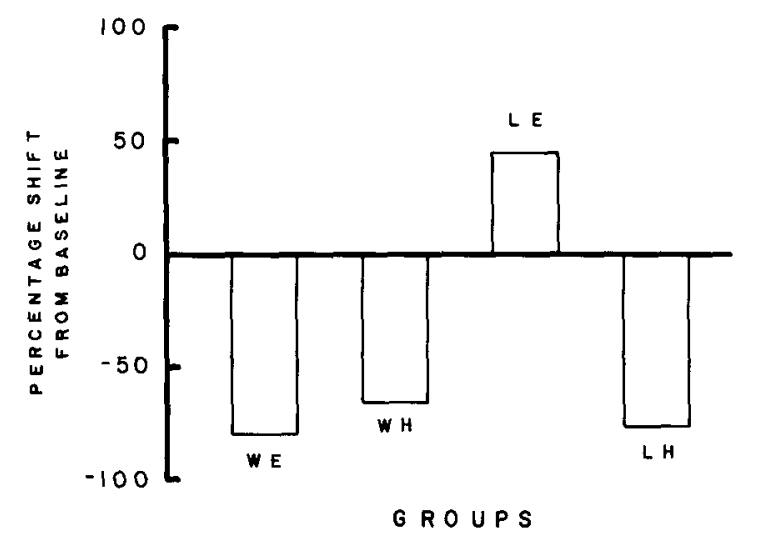

Figure 2. Percentage shift in consumption of saccharin from baseline (Conditioning Trial 1) to the first aversion test (Condjtioning Trial 2) for all groups.

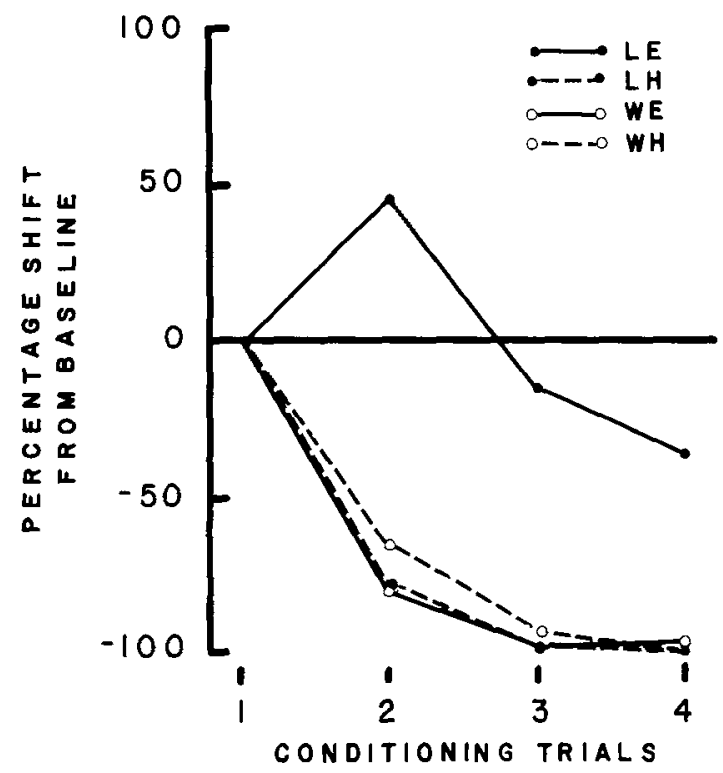

Figure 3. Percentage shift in consumption of saccharin from baseline over repeated conditioning trials for all groups.

percentage shift in consumption from the first conditioning trial to the initial test (see Conditioning Trial 2).

Subjects given control injections following water access in the preexposure phase (Groups WE and WH) significantly decreased consumption following the saccharin- $\mathrm{LiCl}$ pairings $[\operatorname{ts}(5)=4.79$ and 4.16 for Groups WE and WH, respectively]. This decrease was independent of the environment in which the pairing occurred $[t(10)=1.05$; see Figure 2].

Group $\mathrm{LE}$, which was given $\mathrm{LiCl}$ preexposure and the saccharin- $\mathrm{LiCl}$ pairing in the experimental chamber, showed a slight, nonsignificant increase in saccharin consumption following conditioning $[\mathrm{t}(5)=$ 1.06]. However, Group LH, which had received the same $\mathrm{LiCl}$ preexposure as Group LE but was conditioned in the home cage, significantly decreased saccharin consumption $[t(5)=5.37$; see Figure 2]. There were no differences among groups that decreased saccharin consumption on this initial test (all ts $<1.12$ ), although they all differed significantly from Group LE (all ts > 3.93).

With repeated conditioning trials, Groups WE, WH, and LH further decreased saccharin consumption, drinking $0 \mathrm{ml}$ on the final aversion test. Group LE, although initially increasing consumption of saccharin following conditioning, decreased consumption with repeated trials. This decrease, however, was not as dramatic as that seen in the remaining poisoned subjects (see Figure 3). Figure 3 illustrates the percentage shift in saccharin consumption from the initial baseline over repeated conditioning trials.

\section{EXPERIMENT 2}

\section{Method}

The subjects were 24 naive Long-Evans rats, whose age, housing, and maintenance were the same as in Experiment 1. The habituation, preexposure, and conditioning phases were similar to those of Experiment 1, except that the drug given during preexposure and conditioning was $40 \mathrm{mg} / \mathrm{kg}$ morphine sulfate dissolved in distilled water. The final groups during the conditioning phase of Experiment 2 were Groups WE, WH, ME, and MH.

\section{Results}

Over the water-adaptation days, the subjects gradually increased consumption of water, drinking a mean of approximately $16 \mathrm{ml}$ on the final 3 days of water adaptation.

On Day 1 of the preexposure phase, when all subjects were given their 20 -min access to water in the experimental chamber, both Group $M$ and Group W decreased consumption below their previous days' water baseline in the home cage. Figure 4 illustrates this decrease in consumption on the first exposure to the experimental chamber (see Baseline and Preexposure 1).

With repeated access to water in the experimental chamber followed by morphine (Group M) or water (Group W), both groups showed a slight, nonsignificant increase in consumption, although neither group

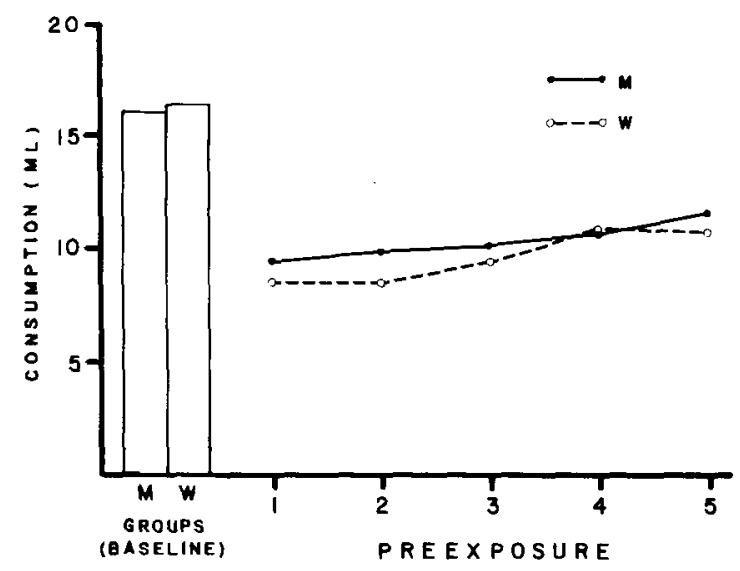

Figure 4. Mean consumption ( $\mathrm{ml}$ ) of water during habituation in the home cage and over the preexposure injections in the distinctive environment for Groups $M$ and $W$. 
approximated its home cage water baseline (see Figure 4). At no point during the preexposure phase did Groups $M$ and $W$ differ in their consumption of water.

During the water recovery sessions following each preexposure injection, Group W returned to its preinjection baseline. Group $\mathbf{M}$ showed a slight, nonsignificant decrease in consumption from its preinjection baseline, indicating that there was no residual effect of preexposure injections on general fluid consumption.

Because the subjects in the two conditioning environments, that is, experimental chamber and home cage, consumed different amounts of saccharin prior to the saccharin-morphine pairing, the subsequent aversions are indexed by the percentage shift in consumption from this initial baseline. Figure 5 illustrates this percentage shift in consumption from the

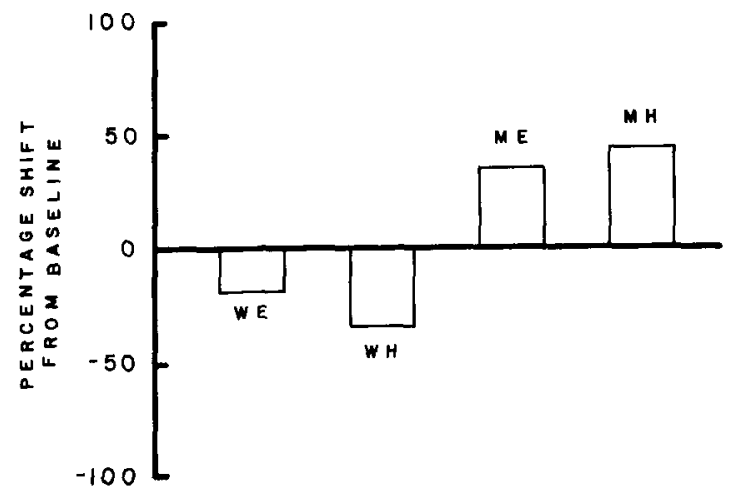

G R U P S

Figure 5. Percentage shift in consumption of saccharin from baseline (Conditioning Trial 1) to the first aversion test (Conditioning Trial 2) for all groups.

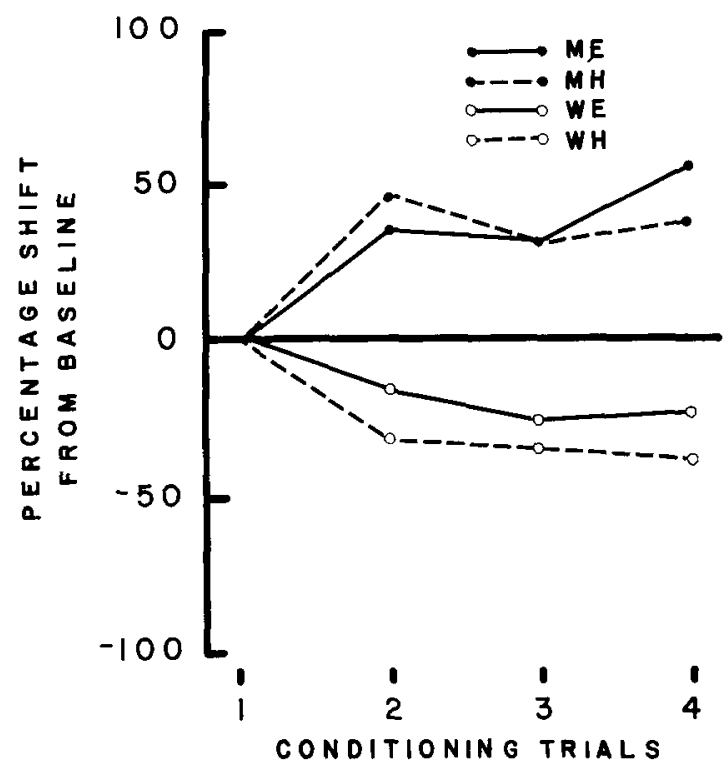

Figure 6. Percentage shift in consumption of saccharin from baseline over repeated conditioning trials for all groups. first conditioning trial to the initial test (Conditioning Trial 2).

As seen in Figure 5, subjects given control injections after water access in the preexposure phase (Groups WE and WH) drank significantly less saccharin following the saccharin-morphine pairing than did subjects preexposed to morphine (Groups $\mathrm{ME}$ and $\mathrm{MH})[\mathrm{t}(10)=6.61$. The decrease in saccharin consumption for Groups WE and WH on this first test was independent of the environment in which the pairing occurred $[t(5)=1.38]$ The increase in saccharin consumption seen in Groups $\mathrm{ME}$ and $\mathrm{MH}$ was aslo independent of the similarity of the preexposure and conditioning environments [ $t(5)=.73]$.

With repeated conditioning trials, saccharin consumption did not change significantly for any group. Figure 6 illustrates the percentage shift in saccharin consumption from the initial baseline over repeated saccharin-morphine pairings.

\section{DISCUSSION}

It is clear from the data that, while the UCS preexposure effect produced by $\mathrm{LiCl}$ was dependent upon the similarity of the preexposure and conditioning environments, this effect was not evident with morphine; that is, animals preexposed to morphine showed attenuated aversions that were independent of the environments in which preexposure and conditioning occurred. That the $\mathrm{LiCl}$-induced preexposure effect was dependent upon the environment replicates the work of Batson and Best (1979) and supports their interpretation that the UCS preexposure effect to $\mathrm{LiCl}$ is due to blocking (see, also, Braveman, 1979; Cappell \& Poulos, 1979; Poulos \& Cappell, 1979). That morphine preexposure attenuated the subsequent acquisition of aversions independently of the environment, however, is not compatible with a blocking interpretation. On the other hand, because morphine is a generally weak UCS in taste aversion conditioning (Riley, Jacobs, \& LoLordo, 1978), it is possible that no conditioning occurred to the environment during morphine preexposure and, as such, blocking by the environmental cues would not be expected when subsequent taste aversion conditioning was attempted (Kamin, 1969). However, the fact that blocking can account for the UCS preexposure effect for $\mathrm{LiCl}$ and amphetamine at doses which produce only moderate aversions, that is, aversions comparable to those induced by morphine in the present study, suggests that the ability of a drug to condition a taste aversion is not necessarily correlated with its tendency to be associated with environmental cues during drug preexposure (see Braveman, 1979; Poulos \& Cappell, 1979). That the morphineinduced preexposure effect appears to be environmentally independent may be best explained in terms of pharmacological tolerance; that is, during preex- 
posure, animals became tolerant to morphine such that when conditioning was subsequently attempted, the effects of morphine were insufficient to condition an aversion. These data support the view that there is no general explanation of the UCS preexposure effect. It appears that the mechanism underlying the attenuated aversions evident after drug preexposure is dependent upon the specific drug administered during the preexposure phase (see Cappell \& LeBlanc, 1977; Gamzu, 1977).

As described, both $\mathrm{LiCl}$ and morphine preexposures attenuated subsequent conditioning. With repeated conditioning trials, however, animals conditioned with $\mathrm{LiCl}$ eventually avoided consumption of saccharin. This reversal of the initial attenuation was not seen with morphine following the multiple saccharin-morphine pairings. That repeated conditioning trials with $\mathrm{LiCl}$ eventuated in an aversion to saccharin suggests that, while blocking may have been the mechanism underlying the $\mathrm{LiCl}$-induced preexposure effect, blocking was not complete; that is, some conditioning strength accrued to saccharin when saccharin was paired with $\mathrm{LiCl}$ in the presence of the previously conditioned contextual cues (see also Riley et al., 1976). That repeated conditioning trials did not result in any aversion to saccharin in previously exposed subjects receiving saccharin-morphine pairings further suggests that tolerance was the mechanism underlying the preexposure effect for morphine and this tolerance was complete.

This difference in the mechanisms underlying the UCS preexposure effects to addictive drugs (morphine) and emetics ( $\mathrm{LiCl}$ ) parallels other investigations that have compared these two chemical classes. These have shown that centrally acting morphine (Amit, Levitan, Brown, \& Rogan, 1977; Riley et al., 1978; Sklar \& Amit, 1977) produced aversions that were very weak, variable, and non-dose-dependent (Zellner \& Riley, Note 1), in marked contrast to the rapidly acquired, robust, and dose-dependent aversions induced by peripherally acting $\mathrm{LiCl}$ (Mikulka, Leard, \& Klein, 1977; Riley et al., 1976; Smith, 1980).

Throughout this paper, it has been suggested that tolerance is a mechanism that is independent of environmental manipulations. This view has recently been challenged by Siegel, who has suggested that tolerance may be due to conditioning and as such is dependent upon the conditioning context, for example, the environment (Siegel, 1975, 1978; Siegel, Sherman, \& Mitchell, 1980). The present experiment, however, does not support Siegel's position that tolerance is environment-dependent. This discrepancy may be due to a number of variables, including dose, injection patterning, and strain of animal. One additional and important variable may be the specific response measure of tolerance. In the present paper, the index of tolerance was a change in a general be- havioral response, for example, a conditioned taste aversion; in Siegel's work, changes in more discrete and physiological responses, for example, rectal temperature and analgesia, following morphine exposure were examined. It is quite possible that the specific mechanism underlying tolerance, that is, pharmacological or conditioning, is in part dependent upon the class of response chosen to index the effects of chronic drug exposure (see Eikelboom \& Stewart, 1979; Stewart \& Eikelboom, 1978; Wikler, 1973).

\section{REFERENCE NOTES}

1. Zellner, D., \& Riley, A. Narcotic-induced conditioned taste aversion: $A$ comparison among morphine, $L A A M$, and methadone. Unpublished manuscript available upon request from the authors.

\section{REFERENCES}

Amit, Z., Levitan, D. E. Brown, Z. W., \& Rogan, F. Possible involvement of central factors in the mediation of conditioned aversion. Neuropharmacology. 1977, 16, 121-124.

Batson, J. D., \& Best, P. J. Drug-preexposure effects in flavoraversion learning: Associative interference by conditioned environmental stimuli. Journal of Experimental Psychology: Animal Behavior Processes, 1979, 5, 273-283.

Braveman, N. S. What studies on pre-exposure to pharmacological agents tell us about the nature of the aversion-inducing agent. In L. M. Barker, M. E. Best, \& M. Domjan (Eds.), Learning mechanisms in food selection. Waco, Tex: Baylor University Press, 1977.

Braveman, N. S. The role of blocking and compensatory conditioning in the treatment pre-exposure effect. Psychopharmacology, 1979, 61, 177-189.

Cain, N. W., \& Baenninger, R. Habituation to illness: Effects of prior experience with the US on the formation of learned taste aversion in rats. Animal Learning \& Behavior, 1977, 5, 359-364.

Cannon, D. S., Baker, T. B., \& Berman, R. F. Taste aversion disruption by drug pretreatment: Dissociative and drug-specific effects. Pharmacology, Biochemistry and Behavior, 1977, 6, 93-100.

Cappell, H., \& LeBlanc, A. E. Conditioned aversion by amphetamine: Rates of acquisition and loss of the attenuating effects of prior exposure. Psychopharmacologia, 1975, 43, 157-162.

Cappell, H., \& LeBlanc, A. E. Gustatory avoidance conditioning by drugs of abuse: Relationships to general issues in research on drug dependence. In N. W. Milgram, L. Krames, \& T. Alloway (Eds.), Food aversion learning. New York: Plenum Press, 1977.

Cappell, H., LeBlanc, A. E., \& Herling, S. Modification of the punishing effects of psychoactive drugs in rats by previous drug experience. Journal of Comparative and Physiological Psychology, 1975, 89, 347-356.

Cappell, H., \& Poulos, C. X. Associative factors in drug pretreatment effects on gustatory conditioning: Cross-drug effects. Psychopharmacology, 1979, 64, 209-213.

Corfield-Sumner, P. K., \& Stolerman, I. P. Behavioral tolerance. In D. E. Blackman \& D. Sanger (Eds.), Contemporary research in behavioral pharmacology. New York: Plenum Press, 1978.

ECKARDT, M. J. Alcohol-induced conditioned taste aversion in rats: Effects of concentration and prior exposure to alcohol. Journal of Studies on Alcohol, 1976, 37, 334-346.

EIKELBoom, R., \& StewART, J. Conditioned temperature effects using morphine as the unconditioned stimulus. Psychopharmacology, 1979, 61, 31-38.

GAmzU, E. The multifaceted nature of taste-aversion inducing 
agents: Is there a single common factor? In L. M. Barker, M. E. Best, \& M. Domjan (Eds.), Learning mechanisms in food selection. Waco, Tex: Baylor University Press, 1977.

GoetT, J., \& KAY, E. Lithium chloride and $\Delta^{9}$-THC lead to conditioned aversions in the pigeon. Psychopharmacology, 1981, 72, 215-216.

Goldstein, A., Aronow, L., \& Kalman, S. M. Principles of drug action: The basis of pharmacology. New York: Wiley, 1974.

Goudie, A. J., \& Thonnton, E. W. Effects of drug experience on drug induced conditioned taste aversions: Studies with amphetamine and fenfluramine. Psychopharmacologia, 1975, 44, 77-82.

Greengard, P. Possible role of cyclic nucleotides and phosphorylated membrane proteins in postsynaptic actions of neurotransmitters. Nature, 1976, 260, 101-108.

J ACoBs, W. J., Zellner, D. A., LoLoRdo, V. M., \& Riley, A. L. The effect of postconditioning exposure to morphine on the retention of a morphine-induced conditioned taste aversion. Pharmacology, Biochemistry and Behavior, 1981, 14, 779-785.

KAMIN, L. J. Predictability, surprise, attention and conditioning. In B. A. Campbell \& R. M. Church (Eds.), Punishment and aversive behavior. New York: Academic Press, 1969.

LEMBerger, L., \& RUBin, A. Physiologic disposition of drugs of abuse. New York: Spectrum, 1976.

Martin, W. R., \& Sloan, J. Neuropharmacology and neurochemistry of subjective effects, analgesia, tolerance, and dependence produced by narcotic analgesics. In W. R. Martin (Ed.), Drug addiction I: Morphine, sedative/hypnotic and alcohol dependence. New York: Springer-Verlag, 1977.

Mikulxa, P. J., LeARD, B, \& KLEIN, S. B. Illness alone (US) exposure as a source of interference with the acquisition and retention of a taste aversion. Journal of Experimental Psychology: Animal Behovior Processes, 1977, 3, 189-201.

Mucha, R. F., \& Kalant, H. Log dose/response curve flattening in rats after daily injections of opiates. Psychopharmacology, $1980,71,51-61$.

Mucha, R. F., Kat.ant, H., \& Linesman, M. A. Quantitative relationships among measures of morphine tolerance and physical dependence in the rat. Pharmacology, Biochemistry and Behavior, $1979,10,397-405$.

Poulos, C. X., \& CAppell, H. An associative analysis of pre- treatment effects in gustatory conditioning by amphetamine. Psychopharmacology, 1979, 64, 201-207.

Riley, A. L., \& Clarke, C. M. Conditioned taste aversions: A bibliography. In L. M. Barker, M. E. Best, \& M. Domjan (Eds.), Learning mechanisms in food selection. Waco, Tex: Baylor University Press, 1977.

Riley, A. L., Jacons, W. J., \& LoLordo, V. M. Drug exposure and the acquisition and retention of a conditioned taste aversion. Journal of Comparative and Physiological Psychology, 1976, 90, 799-807.

Riley, A. L., Jacobs, W. J., \& LoLondo, V. M. Morphineinduced taste aversions: A consideration of parameters. Physiological Psychology, 1978, 6, 96-100.

SiEgEL, S. Evidence from rats that morphine tolerance is a learned response. Journal of Comparative and Physiological Psychology, $1975,89,498-506$.

Sieget, S. Pavlovian conditioning analysis of morphine tolerance. In N. A. Krasnegor (Ed.), Behavioral tolerance: Research and treatment implications (NIDA Research Monograph 18). Washington, D.C: Department of Health, Education and Welfare, 1978.

Siegel, S., Sherman, J. E., \& Mitchell, D. Extinction of morphine and analgesic tolerance. Learning and Motivation, 1980, 11, 289-302.

SkLAR, L. S., \& AM1T, Z. Manipulations of catecholamine systems block the conditioned taste aversion induced by self-administered drugs. Neuropharmacology, 1977, 16, 649-655.

Sмiтh, D. F. Central and peripheral effects of lithium on conditioned taste aversion in rats. Psychopharmacology, 1980, 68, 315-317.

STEWART, J., \& EIxelboom, R. Pre-exposure to morphine and the attenuation of conditioned taste aversion in rats. Pharmacology, Biochemistry and Behavior, 1978, 9, 639-645.

SunRez, E. M. \& BARker, L. M. Effects of water deprivation and prior $\mathrm{LiCl}$ exposure in conditioning taste aversions. Physiology \&ehovior, 1978, 17, 555-559.

WIKLER, A. Conditioning of successive adaptive responses to the initial effects of drugs. Conditional Reflex, 1973, 8, 193-210.

(Manuscript received July 28, 1981; revision accepted for publication October 13, 1981.) 